\title{
XLVIII. An account of a new voltaic battery, being a modification of the construction recommended by Mr. Faraday
}

\section{Mr. James Young}

To cite this article: Mr. James Young (1837) XLVIII. An account of a new voltaic battery, being a modification of the construction recommended by Mr. Faraday, Philosophical Magazine, 10:61, 241-244, DOI: $10.1080 / 14786443708649132$

To link to this article: http://dx.doi.org/10.1080/14786443708649132

曲制 Published online: 01 Jun 2009.

Submit your article to this journal ๘

山 Article views: 2

Q View related articles ¿ 
THE

LONDON AND EDINBURGH

\title{
PHILOSOPHICAL MAGAZINE
}

\author{
A N D \\ JOURNAL OF SCIENCE.
}

[THIRD SERIES.]

$A P R I L 1837$.

XLVIII. An Account of a new Voltaic Battery, being a Modification of the Construction recommended by Mr. Faraday. By Mr. James Young, Chemical Assistant in the Andersonian University.*

[With Figures: Plate IJ.]

A PLAIN working battery, containing a considerable numA ber of pairs of plates, arranged on the principle of the pile of Volta or the trough of Cruickshanks, is the instrument which we habitually have recourse to for illustrating chemical decompositions, and the other effects of voltaic electricity requiring considerable tension. Various constructions of this battery are in use, of which we are concerned only with that originally suggested by Dr. Hare, but of the value of which electricians were not aware till it was clearly demonstrated by Mr. Faraday t. The existence of a defect, however, is fully admitted by Mr. Faraday, in the construction which he recommends. To prevent metallic contact between contiguous copper plates, cartridge paper is interposed between them. The paper becomes saturated with the acid solution used as the exciting liquor, and the acid cannot be washed out of the paper, but is retained by it after the battery is laid aside, and may then occasion the solution of the copper, seeing that zinc no longer enters into a circle with the acid and copper, and

* Communicated by the Author.

† Dr. Hare's paper describing his battery will be found in Plil. Mag., First Series, vol. vii. p. 284; and Mr. Faraday's in Lond. and Edinb. Phil. Mag., vol. viii. p. 114.-EdiT.

Third Series. Vol.10. No. 61, April 1837. 
Tond REdint. Phit. Mag. \&. Toum. Vol.20. Pl.2.

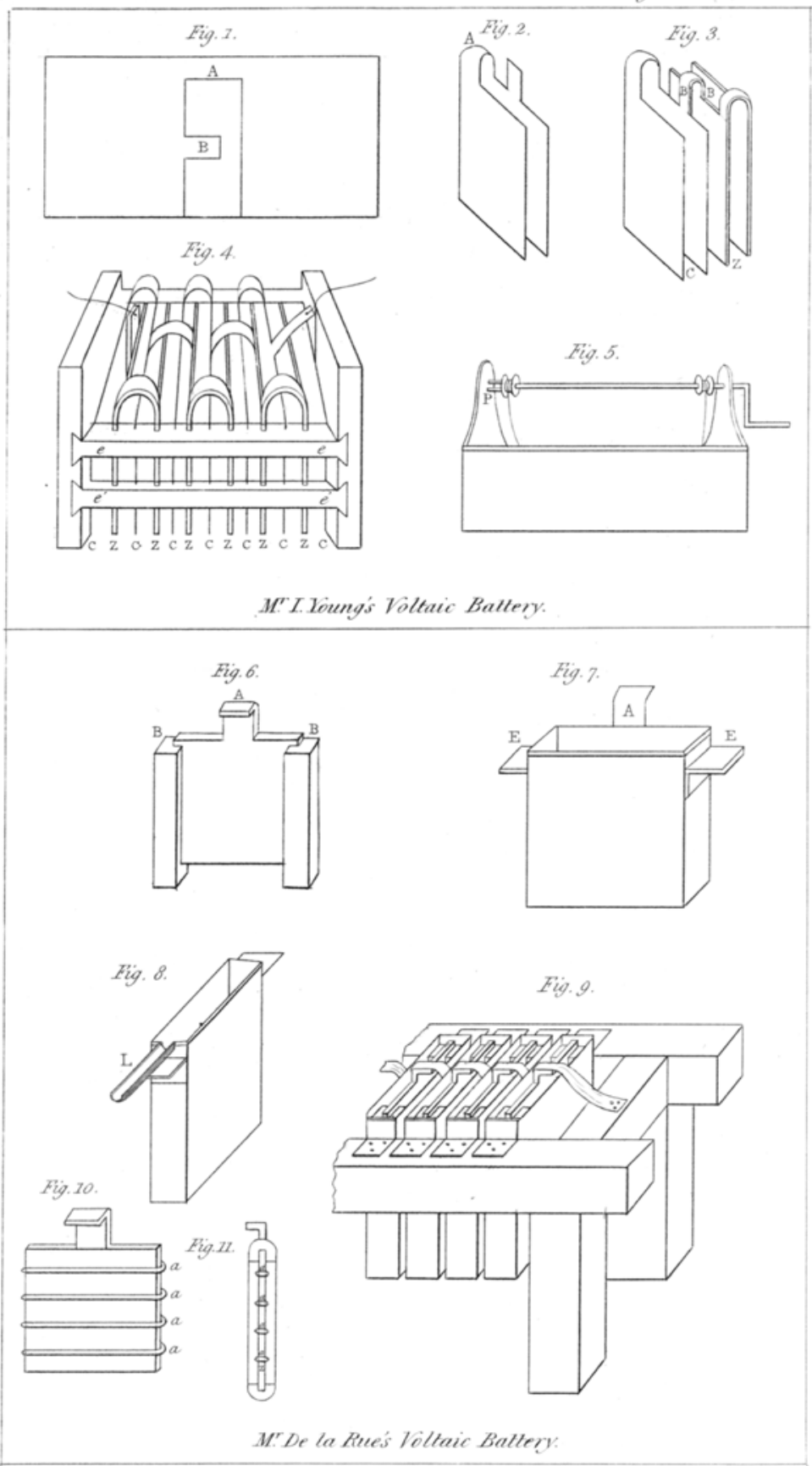




\section{Mr. J. Young's Account of a new Voltaic Battery,}

therefore the latter is unprotected. These papers require likewise to be renewed occasionally, and they give to the construction the character of a temporary arrangement. It is true that glass or porcelain plates may be placed between the contiguous coppers; but these are inconvenient, and, in fact, bring us back to the old construction of the trough partitioned into cells. It is to be noticed too that these copper surfaces, with the paper between them, are lost, and turned to no account in collecting electricity.

After constructing several batteries with the interposed papers, and becoming fully sensible of the annoyance which the papers occasion, an arrangement of the plates suggested itself which does not require interposed papers, and in which both surfaces of the copper as well as of the zinc plates are made available. Within the last eighteen months I have constructed several dozens of instruments of the construction to be described, and having compared them experimentally with batteries of the same extent of copper and zinc on Dr. Hare's construction, I am prepared to state that, from the same surfaces of zinc, electricity the same in quantity and tension is produced in both forms, but that in the new construction this effect is produced with half the quantity of sheet copper, which arises from both sides of the copper plates being presented to surfaces of zinc. The new construction has, I believe, all the advantages of approximation of the plates and compactmess of Dr. Hare's battery, which have been pointed by Mr. Faraday, without the great and acknowledged drawback of the interposed papers.

The sheet copper and sheet zinc to be nsed in this battery are first cut into long ribbons, of the breadth which it is intended to give the plates. Suppose the ribbons two inches broad; both the copper and zinc ribbons are then divided into lengths of five inches, and a portion cut out as in fig. 1. 'The slip is thus divided into two squares of two inches each, which are connected at $\Lambda$, and a piece is left projecting at $B$. The zinc and copper sheets are cut up exactly in the same way. Fig. 1 therefore represents either a single zinc or a single copper plate. The plate is then bent at $A$, and presents the appearance represented in fig. 2 . In fig. 3 , we have two plates, one of copper $\mathrm{C}$, and the other of zinc $\mathrm{Z}$, which are exactly alike in construction, but are placed differently, as shown in the figure. Thin projecting parts B B are soldered together, and this is the only metallic communication between them which is allowed to exist. Fig. 3, therefore, is only one copper and one zinc plate, or it is one pair of plates. Each pair is made up in the same way. In arranging a num- 
ber of pairs to form a battery, they are interlaced so that a copper square comes in between each couple of zinc squares, and a zinc square between each couple of copper squares. It is easy to see how this arrangement can be made, when the plates are in the hand, though it is difficult to describe it. At the positive end of the battery there is a single copper plate, which is soldered at the top to the last double copper plate, as seen in fig. 4 ; which figure represents three pairs properly arranged, and also the manner in which they should be fitted up and kept steadily apart in a wooden frame. This frame consists of two cross-bars, $e e, e^{\prime} e^{\prime}$, in front, and the same behind, dovetailed into solid ends. The channels in the crossbars, for the reception of the edges of the plates, are formed by placing the four cross-bars together, and sawing a little way into one side of them all, every eighth of an inch or so in their length, so as to form a set of parallel grooves. We have by means of this frame a much greater security that no metallic contact will occur between contiguous plates, than when they are separated by wedges of cork, as in Dr. Hare's construction, which may slip out.

The frame and plates are introduced into a trough, which may be of wood or stoneware, containing the exciting liquor. Dr.Hare's revolving arrangement of the two connected troughs may be adopted for this battery, although we have been led to give a preference in practice to a single trough to contain the frame. To the solid ends of the frame are attached two cords, which are fixed to two pulleys, on which they are wound up, on turning a winch, as represented in fig. 5 , by which means the frame and battery can be raised out of the fluid. If the axis (a stout wire) on which these pulleys are fixed can be moved a little backwards and forwards on its bearings, it is easy, by means of a little projecting peg at $P$, which fits into a hole in the side of the pulley, to fix and support the frame in a position above the trough, and out of the exciting fluid, when that is desirable. But the form of the trough to contain the frame and plates may be varied according to the object in view, or the purposes to which the battery is to be applied.

In comparing a battery of the form described above, either with Dr. Hare's or any of the other forms in use, it is to be remembered that the plates or elements of the battery are all of double the size they appear to be, or that in this construction you have half the number of pairs, but each of double the dimensions of a pair in any of the old batteries having the same appearance.

A small battery of this construction, containi:g twelve pairs, 2 I 2 
of two inches breadth, of plates (the size which we have taken above as an example), may be contained in a trough eight inches in length, and will evolve, when its terminal wires are soldered to a Faraday's vol ta-electrometer, six or seven cubic inches of the mixed gases in three or four minutes, with a charge of half an ounce of sulphuric acid and half an ounce of nitric acid, in twenty-four ounces of water, (all by fluid measure, ) and is therefore amply sufficient to demonstrate the decomposition of water on a considerable scale.

It is proper to use the thickest sheet zinc which can be had, in the construction of the plates, although the thinnest sheet copper will suffice, from its being so well supported. When the zinc plates are worn out, the cross-bars may easily be pulled out of the solid ends, and the elements of the battery separated. New zinc plates being soldered to the old coppers, the whole may again be quickly rearranged in the old franie.

Glasgow, Jan. 4, 1837.

XLIX. On the Effects of a Voltaic Battery charged with Solution of Sulphate of Copper. By Mr. W ARREN DE LA Rue.

\section{[With Figures: Plate II.]}

\section{To the Editors of the Philosophical Magazine and Journal.} Gentuemen,

I answer to your query (vol. ix. p. 484, ) as to the relative effects of batteries charged with sulphate of copper or with acids, I beg to submil to your attention the following facts and deductions.

It is well known that in connecting the poles of a battery with a definite length of wire, the wire will become ignited, and continue so for an exceedingly short space of time after immersion in an acid; and if the battery be immersed without connecting the poles and allowed to remain for a few minutes, and the connection be then made,-with the same length of the same wire, - no ignition whatever is produced*. As in this latter case no zinc can have been deposited on the copper plate, prior to the connection of the poles, it follows that this decrease of power must result from some other cause. At the moment of immersion in dilute acid, say sulphuric, the electricity is produced by the combination of the acid with that portion of oxide which is in perfect contact with the zinc plate: when this thin coating of oxide is removed, the zinc plate is then oxidized at the expense of water, hydrogen be-

* A battery regains its former power by exposing the plates to the action of the atmosphere. 